\title{
Research on Cultivation and Development of Graduate Students' Innovation and Entrepreneurship Consciousness
}

\author{
Sirong Chen ${ }^{1} \&$ Mu Zhang ${ }^{1}$ \\ ${ }^{1}$ Shenzhen Tourism College, Jinan University, Shenzhen, China \\ Correspondence: Mu Zhang, Shenzhen Tourism College, Jinan University, Shenzhen, Guangdong Province, \\ China. Tel: 86-138-2438-8695. E-mail: zhangmu@163.com
}

Received: February 7, 2020

Accepted: March 4, 2020 Online Published: March 15, 2020

doi:10.5539/hes.v10n2p45

URL: https://doi.org/10.5539/hes.v10n2p45

\begin{abstract}
At present, it is a common phenomenon in colleges and universities all over the world to carry out innovation and entrepreneurship education. This article takes the graduate students of tourism management major as the research object, and explores the theory and practice of cultivating the innovative entrepreneurship consciousness of tourism management graduate students in colleges and universities through the method of literature and questionnaire. The purpose of the study is to put forward some opinions and suggestions on the innovative entrepreneurship education of graduate students in tourism management.
\end{abstract}

Keywords: tourism management, graduate students, consciousness of innovation and entrepreneurship, higher education

\section{Introduction}

Innovation and entrepreneurship education is aimed at cultivating talents with the basic quality of entrepreneurship and pioneering personality, and is a practical education based on cultivating individual's entrepreneurial consciousness, innovative spirit and innovative entrepreneurial ability. Innovation and entrepreneurship education originated in American business schools and is regarded as one of the most central economic development drivers in the United States. Today, most American universities offer innovative and entrepreneurship programs, and a comprehensive innovation and entrepreneurship education system has been built from primary to graduate school (Jie \& Li, 2018).

The innovation and entrepreneurship education in Chinese universities started late, and the implementation began at the end of the 20th century. The attention of colleges and universities, the relevant policies and support of relevant government departments and local governments has developed rapidly. For example, in February 2019, the General Office of the CPC Central Committee and the General Office of the State Council issued the Implementation Plan for Accelerating the Modernization of Education (2018-2022), which emphasized the "implementation of the innovation and entrepreneurship education reform plan, the employment and entrepreneurship promotion plan for college graduates". At present, China's innovation and entrepreneurship education mainly includes innovation and entrepreneurship competition, innovation and entrepreneurship guidance and education courses, the establishment of innovation and entrepreneurship base platform, the establishment of innovative and entrepreneurship organizations, integration of talent training programs and other types.

At the same time, with the development of science and technology, the tourism industry gradually to innovation, intelligent transformation, which requires tourism talents can have a sense of innovation and entrepreneurship, the development of their own innovative entrepreneurial ability to meet the needs of the industry. In the above background, this paper mainly discusses the role, problems and solutions of the innovative and entrepreneurship consciousness of tourism management graduate students.

\section{Literature Review}

Given that reform is now a constant feature of higher education, rethinking universities and higher education learning systems to promote the mindset and capabilities needed to trigger entrepreneurial initiatives has become paramount and at the same time, the tourism industry itself continues to change in ways which are difficult to predict (Dredge et al., 2019; Secundo \& Moustaghfir, 2016); therefore entrepreneurship has become an 
important subject in many undergraduate and postgraduate programs in hospitality and tourism schools since it aims to prepare and train future entrepreneurs to venture into business (Ahmad, Bakar, \& Ahmad, 2018). From the perspective of tourism students, the embeddedness of entrepreneurship education within their courses is not only considered to be very relevant to assess future employment prospects, but also to enhance students' non-cognitive skills which are most valued by the tourism industry (Daniel, Costa, Pita, \& Costa, 2017). Ndou, Mele and Del Vecchio (2019) analysed the modules and content related to entrepreneurship in the tourism education programs of European universities though a web-based content analysis, and sought to analyse how the main components related to Entrepreneurship education are being structured in these tourism education programs as well as offered advice on what might constitute an effective tourism entrepreneurship education path. Bischoff , Volkmann, and Audretsch (2018) provided an overview of key external stakeholder groups in the university entrepreneur ecosystem and their forms of participation in entrepreneurship education based on a cross-case analysis of 20 European higher education institutions from 19 European countries, and also discussed stakeholders The power and coordination of collaboration and the overall approach to stakeholder management. Deale (2016) applied the findings of their research on entrepreneurial perspectives in the hospitality and tourism industries to help students to develop creativity and critical thinking skills, engage in deeper self-discovery experiences, and understand tourism more fully to help prepare them for entrepreneurial roles.

\section{Research Design}

\subsection{Research Purpose}

This paper investigates the current situation of cultivating the innovative and entrepreneurship consciousness of graduate students in tourism management, and analyses the results of the survey to understand the situation of the educational setting of the graduate students of tourism management, the cognition of the innovative and entrepreneurship elements of the graduate students of tourism management and their willingness, consciousness and ability to innovate and entrepreneurship. The aim is to put forward some opinions and suggestions on the theory and practice of cultivating the sense of innovation and entrepreneurship of graduate students in tourism management.

\subsection{Research Methods}

The study used literature review and questionnaire survey methods to collect data. In the questionnaire part, in order to ensure the authenticity and scientificity of the data, this study first designed the preliminary questionnaire on the basis of reading a large number of literatures, combined with the actual research questions, and secondly, collected data on a small scale, using SPSS21.0 software to test the validity of the questionnaire.

\subsection{Questionnaire Design}

In this study, the questionnaire was designed as a semi-structured questionnaire, including single-choice questions, scale answer questions and open questions, in which the scale answer questions were based on the Likert scale method. The questionnaire consists of seven parts and 42 questions. The first part is the respondent's basic personal information, including gender, grade and whether they have participated in innovation and entrepreneurship competition or practice. The second part is the intention of innovation and entrepreneurship, reference Ning and Ge (2017) on the measurement of entrepreneurial intention, including a total of three topics. The third part is the consciousness of innovation and entrepreneurship, drawing on Lin (2014) on the dimension of entrepreneurship awareness, from many angles to measure the tourism management graduate students' awareness of innovation and entrepreneurship, a total of six topics. The fourth part is the innovation and entrepreneurship ability, mainly combined with Qu, Zhang and Shi (2015) and Cai (2010) on the dimension of entrepreneurship, designed eight questions. The fifth part is innovation and entrepreneurship education, drawing on the use of $\mathrm{Li}$ (2013) scale from the individual and school factors to measure innovation and entrepreneurship education, a total of nine topics. The sixth part is the cognition of the elements of innovation and entrepreneurship, which has 12 questions, which mainly refers to Ning and Ge (2017) in the measurement of the cognitive elements of entrepreneurship. The last part is the open question, only set up a question, to explore the participation in innovation and entrepreneurship for tourism management graduate students awareness, ability or academic performance and other changes.

\section{Empirical Analysis}

The study combined offline questionnaires and online questionnaires, published and collected a total of 335 questionnaires, of which 13 invalid questionnaires were excluded, leaving 322 valid questionnaires. After using SPSS 21.0 software for reliability and validity analysis, it is concluded that the Cronbach' $\alpha$ coefficient is 0.947 , indicating that the research data are of considerable reliability. In addition, the KMO value of this survey is 0.925 , 
and the significance level of Bartlett 's Test of Sphericity is zero, showing that there exists a strong correlative relationship among all the variables, indicating that the questionnaire is valid.

Table 1. KMO and Bartlett's Test

\begin{tabular}{lll}
\hline Kaiser-Meyer-Olkin measure of sampling sufficient degree & .925 \\
\hline Bartlett's Test of & Approximate chi square & 8097.776 \\
Sphericity & df & 703 \\
& Sig. & .000 \\
\hline
\end{tabular}

Table 2. Credibility statistics

\begin{tabular}{ll}
\hline Cronbach's Alpha & Number \\
\hline .947 & 38 \\
\hline
\end{tabular}

Of the participants, 106 were men and 216 were women, accounting for $32.9 \%$ and $67.1 \%$ respectively, and the ratio of men to men was in line with the actual situation of graduate students in tourism management, and 100 have participated in innovation and entrepreneurship competitions or practices, and 222 persons, $31.1 \%$ and $68.9 \%$, respectively, who have not participated in the innovation and entrepreneurship competition or practice. In addition, in order to ensure that the research has sufficient comprehensive coverage, this paper includes graduate students of all grades into the scope of the survey, including 161 graduate students in the first year, 108 graduate students in the second year, and 53 students in the third year of graduate studies.

\subsection{Intention and Consciousness of Innovation and Entrepreneurship}

Through the analysis of the questionnaire, it was found that graduate students in tourism management have a certain degree of enthusiasm to participate in innovation and entrepreneurship, as shown in Figure 1, in the case of appropriate opportunities, the number of people willing to participate in innovation and entrepreneurship and take the risk of delaying the course of work is "very consistent" and "more consistent" accounted for $9.01 \%$ and $32.61 \%$, respectively, a total of up to $42 \%$ or so. The questionnaire also uses the five-point Likert scale to assess the intention of tourism management graduate students to participate in innovation and entrepreneurship during their studies and within three years of graduation, with options 1-5 indicating the following meanings: 1=Strongly disagree, 2=disagree, 3=Neither Agree Nor Disagree, 4=Agree, 5= strongly Agree. The results showed that both during school and within three years of graduation, the proportion of people with Neither Agree nor Disagree was the largest, with an average of 3.09 and 3.06 respectively.

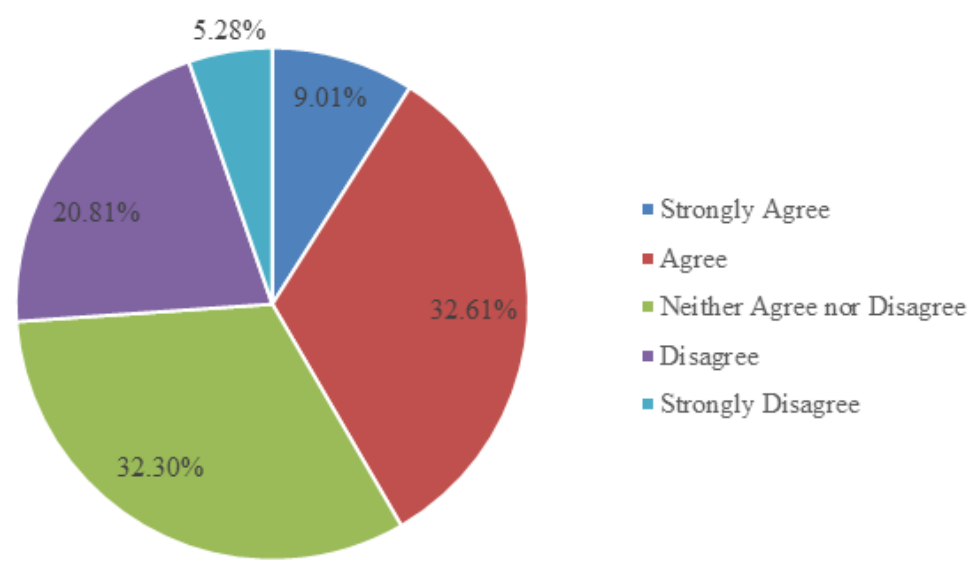

Figure 1. Graduate students' intention of innovation and entrepreneurship

In investigating the innovation and entrepreneurship consciousness of tourism management graduate students, the questionnaire was conducted in combination with three dimensions: behaviour attitude, subjective norms and perceptual behaviour control, and the results showed that the participants' innovative and entrepreneurship consciousness was at a medium and high level. As can be seen from Figure 2, 45.10\% of students are more likely to identify with or identify as an entrepreneur or innovator than to be employed as a non-innovative entrepreneur, almost twice as likely as those who disagree $(19.33 \%)$ and very disagree (3.99\%) combined. In addition, 6.77 percent and 31.69 percent of the respondents were very much liked or agreed with other activities, teachers and 
students were more interested in innovation and entrepreneurship, 40.92 percent of the participants held an uncertain view, accounting for the largest proportion (Figure 3). However, when asked whether difficulties in the process of innovation and entrepreneurship would be easily abandoned, only about 13 per cent of the respondents said they would give up easily, and more than half were more likely to insist on overcoming them (Figure 4).

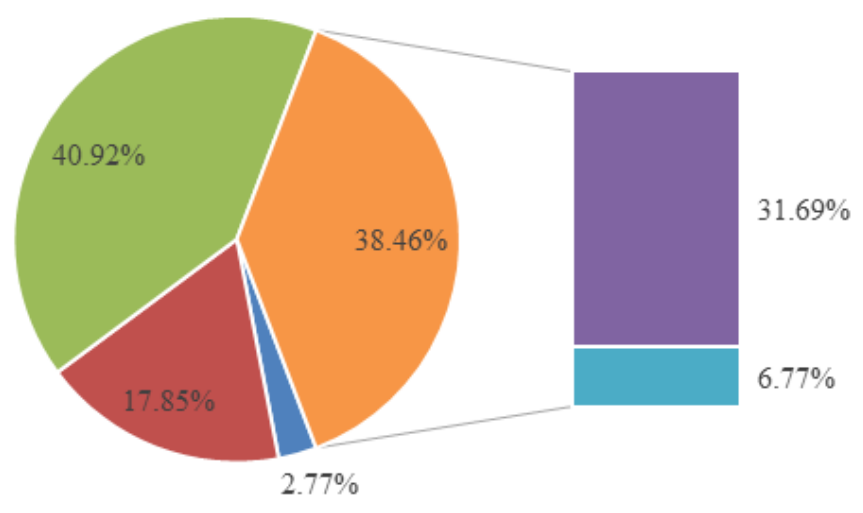

- Strongly Disagree $\quad$ Disagree $\quad$ " Neither Agree nor Disagree " Agree = Strongly Agree

Figure 2. Attitude towards innovation and entrepreneurship

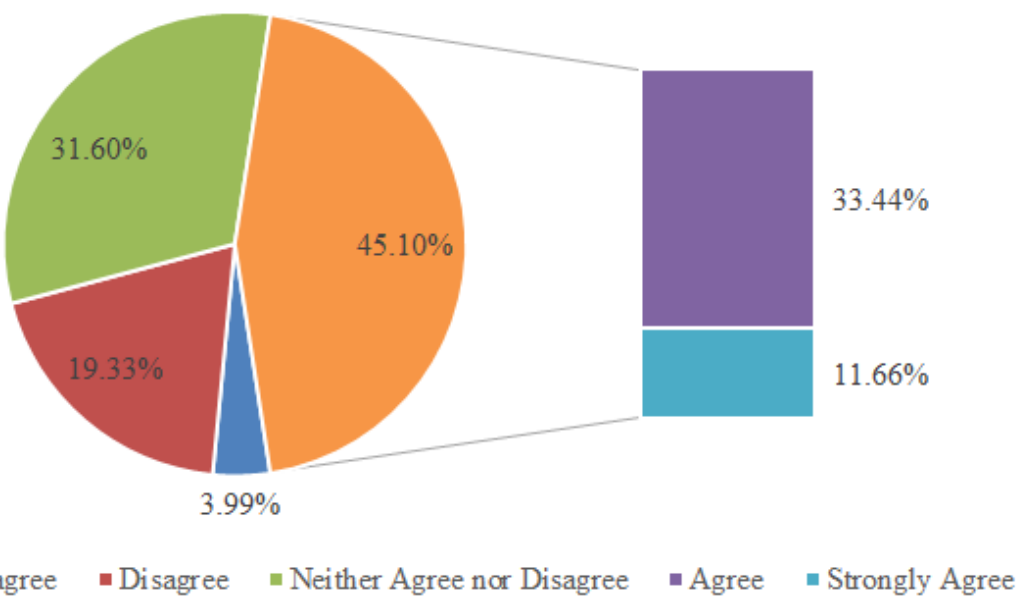

Figure 3. Subjective norms for innovation and entrepreneurship

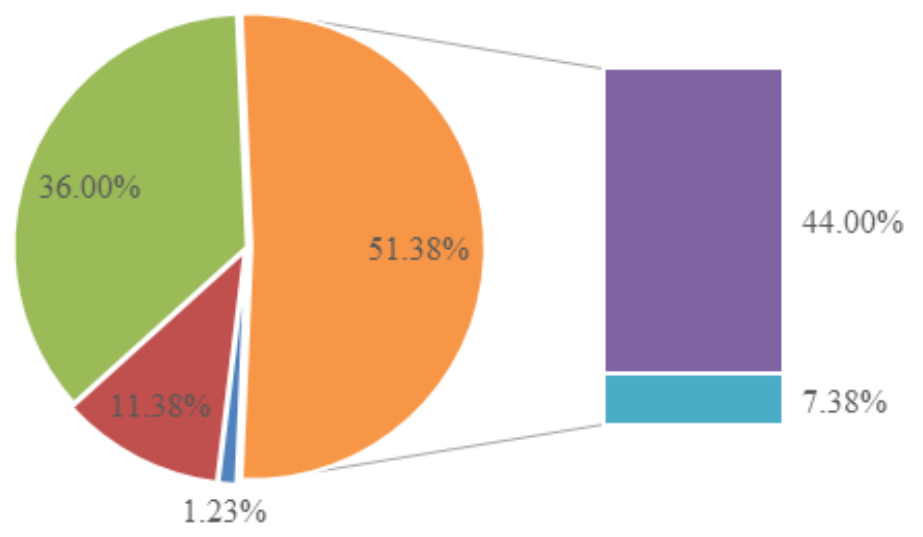

- Strongly Disagree $\square$ Disagree $=$ Neither Agree nor Disagree $\quad$ Agree $\square$ Strongly Agree

Figure 4. Perceived behaviour of innovation and entrepreneurship 
Therefore, in the current students' overall innovation and entrepreneurship intention and consciousness are relatively good, colleges and universities can implement the way of encouragement and guidance, combined with the interpretation level theory, to find the innovative and entrepreneurship path to help tourism management graduate students integrate their long-term goals. The interpretation level theory holds that self-control refers to the way people make decisions or complete tasks based on the high level of interpretation of events as a whole rather than locally low levels of interpretation (Fujita, Trope, Liberman, \&Levin-Sagi, 2006), where high levels of interpretation are core, intrinsic, and tasks. De-backgrounding and goal-related, for example, thinking that reading is about acquiring knowledge, not looking at text mechanically (Trope\& Liberman, 2003). In cultivating the sense of innovation and entrepreneurship of tourism management graduate students, colleges and universities should guide them to take a long-term view and focus on the core benefits that participation in innovation and entrepreneurship can bring to them, rather than limiting their vision to the present or to participating in the innovation and entrepreneurship itself.

\subsection{Ability of Innovation and Entrepreneurship}

From the five dimensions of recruiting partners, rational distribution of rights and responsibilities, capital preparation, resource integration and resource management, this study investigate the innovative entrepreneurial ability of tourism management graduate students. By analysing the results of the questionnaire and making a descriptive analysis chart (Figure 5), it can be seen from the line chart that the proportion of respondents who have the highest uncertainty about whether they have the ability is highest, with ratios of $39.94 \%, 41.21 \%$, $42.49 \%, 46.96 \%$ and $46.65 \%$, respectively. Among them, the subjects had the greatest uncertainty about whether they had the ability to integrate resources.

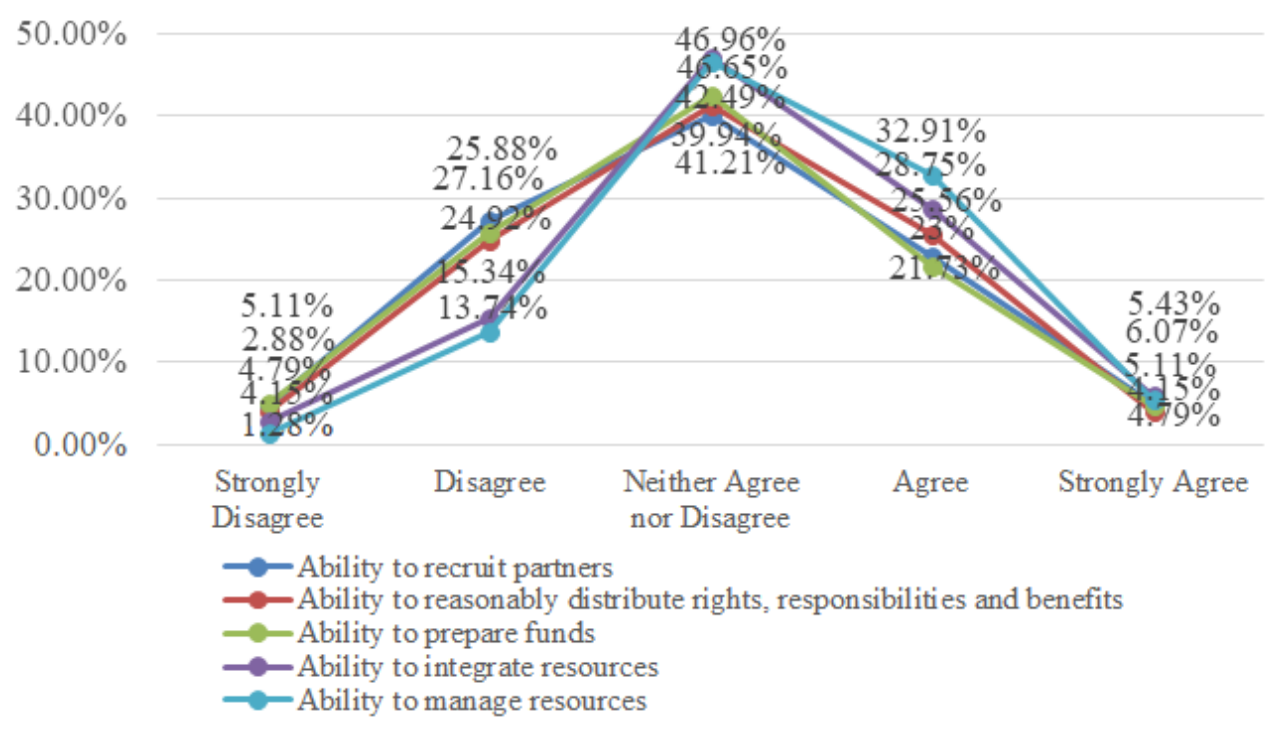

Figure 5. Ability of Innovation and entrepreneurship

Based on this, colleges and universities should cultivate the innovative and entrepreneurship ability of tourism management graduate students to help them better participate in innovation and entrepreneurship. On the one hand, colleges and universities should cultivate students' comprehensive ability, including organizational ability, cooperation ability, innovation ability and so on. On the other hand, colleges and universities should focus on cultivating students' specific abilities related to innovation and entrepreneurship, such as cultivating students' recruitment partners, rational allocation of rights and responsibilities, capital preparation, resource integration and resource management.

\subsection{Innovation and Entrepreneurship Education}

In the field of innovation and entrepreneurship education, the questionnaire surveyed the individual and the university two dimensions, to assess the tourism management graduate students to actively choose to participate in innovation and entrepreneurship education and the degree of satisfaction with the school to provide innovative and entrepreneurship education-related support ( 1 is strongly disagree or highly dissatisfied, 5 is strongly agreement or highly satisfied). The results showed that the tendency of individuals to actively choose to 
participate in innovation and entrepreneurship education was at the medium level, with an average of 2.95, and the satisfaction of the support related to innovative and entrepreneurship education provided by schools was at the medium-upper level, with an average of 3.30. In addition, $41.59 \%$ of the participants were satisfied and $10.16 \%$ were highly satisfied with the emphasis placed on innovation and entrepreneurship education by school leaders (Figure 6).

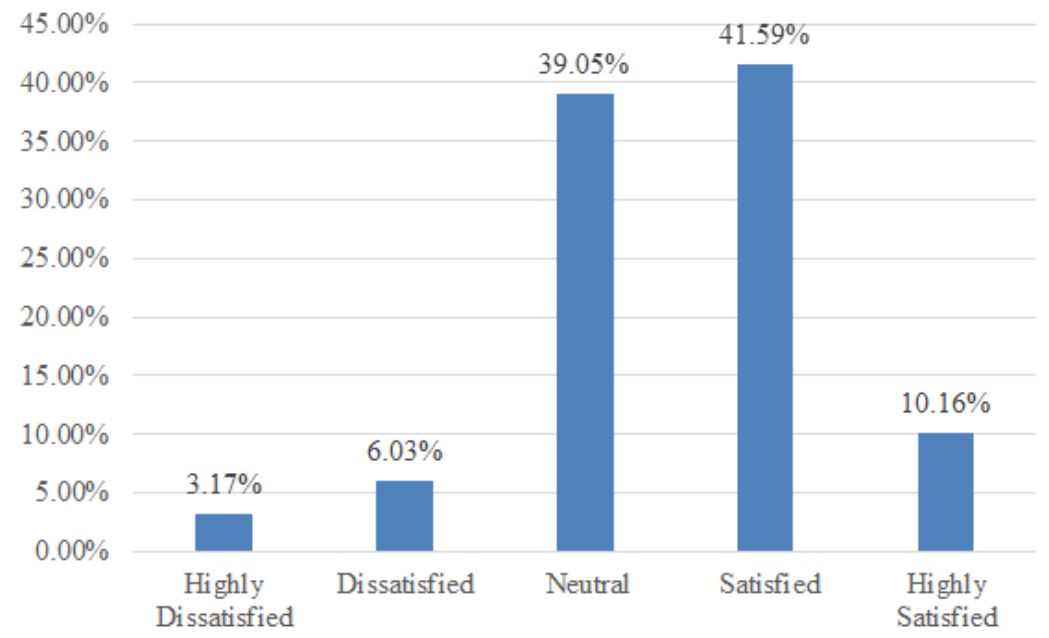

Figure 6. Satisfaction with the school's emphasis on innovation and entrepreneurship education

Therefore, in the field of innovation and entrepreneurship education, colleges and universities should take the needs of students as the guide, and further strengthen the relevant curriculum of innovation and entrepreneurship, practice system construction, off-campus experts or entrepreneurs lecture arrangements. At the same time, students should be further guided to participate in innovative and entrepreneurship education courses and lectures, innovation entrepreneurship skills training or simulation exercises, and innovation entrepreneurship contest activities.

\subsection{Cognition of Innovation and Entrepreneurship Factors}

The weight of the cognitive elements of innovation and entrepreneurship is obtained by calculation (Figure 7). It can be seen that key technologies and intellectual support have the greatest impact on innovation and entrepreneurship behaviour, but the remaining eleven factors, in addition to the concept of family, the weight difference will not be too large, reflecting the students' attention to the concept of innovation and entrepreneurship, social support, management resources and innovative entrepreneurial environment.

Table 3. The weight of cognitive elements of innovation and entrepreneurship

\begin{tabular}{lll}
\hline Elements & Factors & Weight \\
\hline $\begin{array}{l}\text { The concept of } \\
\text { innovation and entrepreneurship }\end{array}$ & Consciousness of innovation and entrepreneurship & 0.083 \\
$(0.165)$ & & \\
Social support & Opportunities for innovation and entrepreneurship & 0.082 \\
$(0.173)$ & Policy support & 0.087 \\
Management resources & The atmosphere of the society & 0.086 \\
$(0.268)$ & Operation management team & 0.087 \\
& Business network and interpersonal relationship & 0.089 \\
Environment for & Key technical and intellectual support & 0.092 \\
innovation and entrepreneurship & Support from school leaders & 0.080 \\
$(0.393)$ & & \\
& The concept of family & 0.059 \\
& Economic development situation & 0.079 \\
& Benefits for independent innovation and entrepreneurship & 0.088 \\
& The help of subject education & 0.089 \\
\hline
\end{tabular}

This shows that colleges and universities should improve the relevant support for tourism management graduate 
students from the point of view of the elements of innovation and entrepreneurship. Provide support for management teams, business networks, relationships, key technologies and intellectual support in terms of resources related to start-ups. In the community's support for innovation and entrepreneurship, to identify, affirm and support students' innovative and entrepreneurship learning and practice. In terms of awareness and opportunities for innovation and entrepreneurship, students are provided with a variety of opportunities or platforms for participating in innovative and entrepreneurship learning and practice, for example, university-enterprise cooperation, building university entrepreneurship parks, etc. In the innovation and entrepreneurship environment, schools, departments, teachers to strengthen the importance of students innovation and entrepreneurship.

\section{Conclusion}

Through the questionnaire survey on the innovation and entrepreneurship of graduate students in tourism management, this paper explores the theory and practice of cultivating the innovation and entrepreneurship education of graduate students in tourism management from many dimensions, and draws the following five main conclusions:

First, tourism management graduate students have a good basis for innovation and entrepreneurship at the subjective cognitive level. They have a certain enthusiasm to participate in innovation and entrepreneurship, and the awareness of innovation and entrepreneurship is at a medium high level.

Second, a large part of the tourism management graduate students have uncertain attitude about their ability of innovation and entrepreneurship, so colleges and universities need to provide them with targeted training and help.

Third, the tendency of students to actively choose to participate in innovation and entrepreneurship education and their support for innovation and entrepreneurship education provided by schools need to be improved.

Fourth, the resources related to innovation and entrepreneurship, the support of society for innovation and entrepreneurship, the awareness and opportunity of innovation and entrepreneurship, and the environment of innovation and entrepreneurship are all key factors affecting the occurrence of innovation and entrepreneurship.

Fifth, the answers to open questions show that tourism management graduate students have a basic positive view of participating in innovation and entrepreneurship, and they believe that participating in innovation and entrepreneurship can improve their comprehensive ability. However, there are also a few views that blindly participate in innovation and entrepreneurship is not very helpful, in the economic situation is not suitable for entrepreneurship.

\section{Acknowledgements}

This work was supported by the Degree and Graduate Education Reform Key Projects of Guangdong Province, and the title is Exploration and Practice of Postgraduate Cultivation in Incorporating Innovation and Entrepreneurship Consciousness. Also, it was supported by the project of China Higher Education Association Thirteenth Five-Year Plan for Scientific Research in Higher Education (Grant number: 2018SYSZD08).

\section{References}

Ahmad, S. Z., Bakar, A. R. A., \& Ahmad, N. (2018). An evaluation of teaching methods of entrepreneurship in hospitality and tourism programs. The International Journal of Management Education, 16(1), 14-25. https://doi.org/10.1016/j.ijme.2017.11.002

Bischoff, K., Volkmann, C. K., \& Audretsch, D. B. (2018). Stakeholder collaboration in entrepreneurship education: An analysis of the entrepreneurial ecosystems of European higher educational institutions. The Journal of Technology Transfer, 43(1), 20-46. https://doi.org/10.1007/s10961-017-9581-0

Cai, X. D. (2010). A study on entrepreneurship education based on tacit knowledge in universities. Doctoral dissertation, Shanghai: East China normal university.

Daniel, A. D., Costa, R. A., Pita, M., \& Costa, C. (2017). Tourism Education: What about entrepreneurial skills?. Journal of Hospitality and Tourism Management, 30, 65-72. https://doi.org/10.1016/j.jhtm.2017.01.002

Deale, C. S. (2016). Entrepreneurship education in hospitality and tourism: insights from entrepreneurs. Journal of Teaching in Travel \& Tourism, 16(1), 20-39. https://doi.org/10.1080/15313220.2015.1117957

Dredge, D., Schott, C., Daniele, R., Caton, K., Edelheim, J., \& Munar, A. M. (2015). The tourism education futures initiative. Anatolia, 26(2), 340-346. https://doi.org/10.1080/13032917.2014.930773

Fujita, K., Trope, Y., Liberman, N., \& Levin-Sagi, M. (2006) .Construal levels and self-control. Journal of 
Personality and Social Psychology, 90(3), 351-367. https://doi.org/10.1037/0022-3514.90.3.351

Jie, Q. Y., \& Li, L. (2018). Exploration and Practice of "Broad-spectrum" Innovation and Entrepreneurship Education in Universities in UK and USA. Contemporary Youth Research, 4, 92-97.

Li, J. W. (2013). Research on the influence of entrepreneurship education on university students' entrepreneurial intentions (Unpublished doctoral dissertation). Nankai University, Tianjin, China.

Lin, Y. (2014). The probe into the current situation of the entrepreneurship awareness for the college students. Doctoral dissertation, Hangzhou: China.

Ndou, V., Mele, G., \& Del Vecchio, P. (2019). Entrepreneurship education in tourism: An investigation among European Universities. Journal of Hospitality, Leisure, Sport \& Tourism Education, 25, 100175. https://doi.org/10.1016/j.jhlste.2018.10.003

Ning, M. D., \& Ge, B. S. (2017). Influence mechanism study of entrepreneurship education on entrepreneurial behaviour. China Higher Education, 10, 55-57.

Qu, J. Y., Zhang, C. Q., \& Shi, Y. T. (2015). Research on the impact of network entrepreneurship education on nascent network entrepreneurial behaviours of college student. Science-Technology and Management, 17(6), $108-114$.

Secundo, G., \& Moustaghfir, K. (2016). Rethinking the university system: a strategic roadmap towards the entrepreneurial university model. In Creating Technology-Driven Entrepreneurship (pp. 115-148). Palgrave Macmillan, London. https://doi.org/10.1057/978-1-137-59156-2_5

Trope, Y., \& Liberman, N. (2003) .Temporal construal. Psychological Review, 110(3), 403-421. https://doi.org/10.1037/0033-295X.110.3.403

\section{Copyrights}

Copyright for this article is retained by the author(s), with first publication rights granted to the journal.

This is an open-access article distributed under the terms and conditions of the Creative Commons Attribution license (http://creativecommons.org/licenses/by/4.0/). 